\title{
CAPÍTULO 10: EDUCAÇÃO EMPREENDEDORA NOS CURSOS TÉCNICOS: UMA ANÁLISE QUANTI-QUÁLITATIVA DO CASO DOS CURSOS DE ELETRÔNICA E ELETROTÉCNICA DO IFPE
}

\author{
CAPÍTULO 10: EDUCACIÓN EMPRESARIAL EN LOS CURSOS TÉCNICOS: UNA \\ ANÁLISIS CUANTI-CUALITATIVA DEL CASO DE LOS CURSOS DE \\ ELECTRÓNICA E ELECTROTÉCNICA DEL IFPE
}

\section{CHAPTER 10: ENTREPRENEURSHIP EDUCATION IN TECHNICIAN COURSES: A QUANTI-QUALITATIVE ANALYSIS OF ELECTRONICS AND ELECTRICAL TECHNICIAN COURSES AT IFPE}

\author{
Welton Pereira da Luz Felix ${ }^{1}$; Ruben Sostenes Gomes de Melo²; Renata Cristine de Sá Pedrosa Dantas ${ }^{3}$
}

DOI: $\underline{\text { https://doi.org/10.31692/978-65-88970-03-4.156-173 }}$

\begin{abstract}
RESUMO
É possível perceber o crescente aumento na atenção mundial em relação a educação empreendedora e o interesse em sua aplicação por parte de grandes países e organizações. O desemprego e a crise econômica são, atualmente, alguns dos principais fatores responsáveis pelo crescimento do empreendedorismo no Brasil. Visto isso, este trabalho tem como objetivo geral realizar a identificação dos conteúdos de educação empreendedora que estão sendo trabalhados nos cursos Técnico em Eletrônica e Técnico em Eletrotécnica do Instituto Federal de Pernambuco - Campus Recife. Foram analisados documentos oficiais do Instituto Federal de Pernambuco, incluindo documentos do campus Recife e dos cursos Técnico em Eletrônica e Técnico em Eletrotécnica. Aos discentes, foi aplicado um questionário online com questões fechadas e abertas que teve como objetivo identificar o ponto de vista dos estudantes dos cursos técnicos estudados em relação ao tema do trabalho, bem como sua ligação com a instituição e sua posição na sociedade como um todo. Por meio dos resultados obtidos foi possível observar que a maior parte dos estudantes tem interesse em empreender e possuem boa parte das características empreendedoras, apesar disso grande parte dos alunos não tem conhecimento sobre empreendedorismo. A educação empreendedora nos cursos estudados tem maior destaque na disciplina "Empreendedorismo", onde são abordados temas relacionados a noções de empreendedorismo, identificação de habilidades e competências empreendedoras e a identificação de oportunidades de negócios. Conclui-se que o Instituto Federal de Pernambuco - Campus Recife poderia tratar de forma mais ampla a educação empreendedora, tendo em vista o grande interesse por parte de seus estudantes, assim trazendo o empreendedorismo à tona desde o início dos cursos, através de eventos e programas tendo como objetivo preparar cada vez melhor os discentes da instituição para a atualidade do mercado e até mesmo tratando o empreendedorismo de maneira transdisciplinar, com formação aos professores para que cada um possa desenvolver trabalhos em suas disciplinas.

Palavras-Chave: Educação Empreendedora, Empreendedorismo, Cursos Técnicos.
\end{abstract}

\section{RESUMEN}

Es posible notar el creciente aumento de la atención global en relación a la educación emprendedora y el interés en su aplicación por parte de grandes países y organizaciones. El desempleo y la crisis económica son actualmente algunos de los principales factores responsables del crecimiento de la actividad empresarial en Brasil. En vista de esto, este trabajo tiene como el objetivo general la identificación de los contenidos educativos empresariales que se están trabajando en los cursos Técnico en Electrónico y Técnico en Electrotécnico en el Instituto Federal de Pernambuco - Campus

1 Aluno do Curso Técnico em Eletrônica, Instituto Federal de Pernambuco wplf@ discente.ifpe.edu.br

2 Aluno do Curso Técnico em Eletrônica, Instituto Federal de Pernambuco rsgm@discente.ifpe.edu.br

${ }^{3}$ Doutora em Ciência da Computação pelo Centro de Informática/UFPE, Professora do Instituto Federal de Pernambuco - Campus Recife, renatadantas@recife.ifpe.edu.br 
Recife. Se analizaron documentos oficiales del Instituto Federal de Pernambuco, incluidos documentos del campus Recife y de los cursos de Técnico en Electrónico y Técnico en Electrotécnico. A los estudiantes se les aplicó un cuestionario en línea con preguntas cerradas y abiertas que tuvo como objetivo identificar el punto de vista de los estudiantes de los cursos técnicos cursados en relación al tema de trabajo, así como su vinculación con la institución y su posición en la sociedad en su conjunto. A través de los resultados obtenidos se pudo observar que la mayoría de los estudiantes están interesados en la iniciativa empresarial y tienen una buena parte de las características empresariales, a pesar del hecho de que la mayoría de los estudiantes no tienen conocimiento sobre el tema. La educación emprendedora en los cursos estudiados es más destacada en la disciplina "Empreendedorismo", donde se abordan temas relacionados con las nociones de la actividad empresarial, identificación de habilidades y competencias emprendedoras y la identificación de oportunidades de negocio. Se concluye que el Instituto Federal de Pernambuco - Campus Recife podría tratar la educación emprendedora de manera más amplia, dado el gran interés de sus estudiantes, poniendo así la iniciativa empresarial en un primer plano desde el inicio de los cursos, a través de eventos y programas con el objetivo de preparar mejor a los estudiantes de la institución para el mercado actual e incluso tratar la actividad empresarial de manera transdisciplinar, con capacitación a los docentes para que cada uno pueda desarrollar proyectos en sus asignaturas.

Palabras Clave: Educación Empresarial, Iniciativa Empresarial, Cursos Técnicos.

\section{ABSTRACT}

It is possible to notice the increasing global attention to entrepreneurship education and the interest in its application by large countries and organizations. Unemployment and the economic crisis are currently some of the main factors responsible for the growth of entrepreneurship in Brazil. Therefore, this work has the general objective of identifying the contents of entrepreneurial education that are being worked on in the courses Electronics Technician and Electrical Technician of the Federal Institute of Pernambuco - Recife Campus. Official documents of the Federal Institute of Pernambuco were analyzed, including documents of the Recife Campus and the courses Electronics Technician and Electrical Technician. An online questionnaire with closed and open questions was applied to the students, with the objective of identifying the point of view of the students of the technical courses studied in relation to the subject of work, as well as their connection with the institution and their position in society as a whole. Through the results obtained it was possible to observe that most of the students are interested in entrepreneurship and have a good part of the entrepreneurial characteristics, in spite of that most of the students do not have knowledge about entrepreneurship. Entrepreneurial education in the courses studied has greater prominence in the subject "Empreendedorismo", where themes related to notions of entrepreneurship, identification of entrepreneurial skills and competences and the identification of business opportunities are approached. It is concluded that the Federal Institute of Pernambuco - Recife Campus could treat in a more ample form the entrepreneur education, owing to the great interest by its students, thus bringing the entrepreneurism to the surface since the beginning of the courses, through events and programs having as objective to prepare each time better the students of the institution for the actuality of the market and even treating the entrepreneurism in a transdisciplinary way, with formation to the teachers so that each one can develop works in its disciplines.

Keywords: Entrepreneurial Education, Entrepreneurship, Technical Courses.

\section{INTRODUÇÃO}

Segundo dados do Instituto Brasileiro de Geografia e Estatística (IBGE, 2020), a taxa de desemprego no último trimestre de 2019 foi de $11 \%$, valor que representa cerca de 11,632 milhões de brasileiros. Em 2017, segundo o IBGE (2018), 676.444 empresas entraram no mercado, ocupando 1.694 .270 pessoas. Esses dados mostram que a quantidade de novas 
empresas vem aumentando, como uma saída a falta de empregos. O desemprego e a crise econômica são, atualmente, alguns dos principais fatores responsáveis pelo crescimento do empreendedorismo no Brasil.

Nos seus mais de 110 anos de história, o Instituto Federal de Educação, Ciência e Tecnologia de Pernambuco teve como objetivo a formação de mão de obra qualificada para ocupação de postos de trabalho (IFPE, 2012). Apesar disso, nos últimos anos é notável o crescimento do incentivo ao empreendedorismo por parte da instituição. Em agosto de 2020 foi aprovada a fundação da primeira empresa júnior do IFPE (IFPE, 2020a). Também ocorrem na instituição eventos relacionados a empreendedorismo e existem programas realizados por instituições parceiras, como o Programa Internacional Despertando Vocações para Gestão e Tecnologias (PDVGT), realizado pelo Instituto Internacional Despertando Vocações, que tem como objetivo a construção de atividades locais que possam estimular a criatividade, inovação tecnológica, utilização das boas práticas de gestão para o estímulo da proatividade, autonomia e empreendedorismo (IIDV, 2018?).

É possível perceber o crescente aumento na atenção mundial em relação a educação empreendedora e o interesse em sua aplicação por parte de grandes países e organizações, como a Organização para Cooperação e Desenvolvimento Econômico (OCDE). O Brasil ainda sofre algumas dificuldades nesse quesito, mas iniciativas como o Programa Nacional de Educação Empreendedora (PNEE), criado pelo SEBRAE, vêm auxiliando instituições de ensino a disseminar a cultura empreendedora (SEBRAE, 2019?).

No estado de Pernambuco, organizações como o parque tecnológico Porto Digital, em Recife, vêm atuando na expansão do empreendedorismo, criando ambientes favoráveis para a criação de novos empreendimentos, além disso existem outras estruturas como o Armazém da Criatividade de Caruaru, localizado no interior do estado, também ligada ao Porto Digital (PORTO DIGITAL, 2017a?, 2017b?).

Em virtude disso, este trabalho tem como objetivo geral realizar a identificação dos conteúdos de educação empreendedora que estão sendo trabalhados nos cursos Técnico em Eletrônica e Técnico em Eletrotécnica do Instituto Federal de Pernambuco - Campus Recife.

Os objetivos específicos foram definidos de modo que conduzissem o trabalho para o alcance do objetivo geral. São eles: a realização de um levantamento curricular acerca dos conteúdos de empreendedorismo trabalhados nos cursos técnicos estudados, a identificação junto aos docentes em relação à percepção sobre a importância da educação empreendedora na formação profissional no curso, a identificação junto aos discentes em relação à apreensão da educação empreendedora como fomentadora da sua formação profissional e a apresentação 
de alternativas, a partir dos levantamentos, para o desenvolvimento da educação empreendedora nos cursos técnicos em Eletrônica e Eletrotécnica do IFPE - Campus Recife.

Dessa forma, serão desenvolvidos os principais conceitos acerca do empreendedorismo e da educação empreendedora.

\section{FUNDAMENTAÇÃO TEÓRICA}

De acordo com Baggio (2014) o empreendedorismo é a arte de fazer acontecer com criatividade e motivação. Um empreendedor está sempre buscando entender e aprender mais sobre si mesmo. "Os empreendedores não apenas definem situações, mas também imaginam visões sobre o que desejam alcançar" (FILION, 2000, p. 3). Empreendedores são criativos e conseguem tomar melhores decisões.

Anteriormente, acreditava-se que o empreendedorismo era algo que nascia com o indivíduo, que apenas algumas pessoas possuíam o “dom de empreender". Entretanto, atualmente se acredita que o empreendedorismo pode ser ensinado e aprendido por qualquer pessoa (DORNELAS, 2001). Criatividade e habilidades empreendedoras podem ser incorporadas nas metodologias de ensino e as instituições educacionais podem encorajar especialidades relacionadas com inovação (BANERJI et al., 2010).

Malacarne, Brunstein e Brito (2014) apontam que normalmente os sistemas educacionais buscam formar empregados e que o estímulo do empreendedorismo enfrenta resistências e conflitos, o que gera impacto para docentes e estudantes.

A educação empreendedora permite que os estudantes desenvolvam importantes características, tais como: bom uso de recursos, imaginação, entre tantas outras.

Segundo Filion (2000) o importante no ensino do empreendedorismo não é o que se aprende, mas sim como se aprende.

Os princípios pedagógicos do IFPE têm como um dos objetivos formar um profissional flexível frente a novas condições de ocupação no mundo do trabalho, por meio de um ambiente interdisciplinar (IFPE, 2012).

De acordo com Filion (2000) um programa de empreendedorismo deve se concentrar no desenvolvimento do conceito de si e na aquisição de know-how, que deve ser focado na definição de situações. Por sua vez, essa é a principal atividade dos empreendedores: conhecer e entender mercados, identificar oportunidades de negócios, selecionar objetivos, imaginar visões, projetar e estruturar organizações e dar vida a essas organizações

Dornelas (2001) diz que as habilidades de um empreendedor podem ser divididas em 
três áreas: técnicas, gerenciais e características pessoais. As habilidades técnicas envolvem saber escrever, saber ouvir as pessoas e captar informações, ser um bom orador, ser organizado, saber liderar, saber trabalhar em equipe e possuir know-how técnico na área de atuação. As habilidades gerenciais estão relacionadas com a criação, desenvolvimento e gerenciamento de uma nova empresa, tais como: marketing, administração, finanças, operacional, produção, tomada de decisão, controle das ações da empresa e ser um bom negociador. Já dentre as características pessoais, temos: ser disciplinado, assumir riscos, ser inovador, ser orientado a mudanças, ser persistente e ser um líder visionário (quadro 1).

Quadro 1: Habilidades empreendedoras.

\begin{tabular}{|l|l|l|}
\hline \multicolumn{1}{|c|}{ Habilidades Técnicas } & Habilidades Gerenciais & Características pessoais \\
\hline $\begin{array}{l}\text { Saber ouvir as pessoas e } \\
\text { captar informações }\end{array}$ & Marketing & Ser disciplinado \\
\hline Ser um bom orador & Administração & Assumir riscos \\
\hline Ser organizado & Finanças & Ser inovador \\
\hline Saber liderar & Operacional & Ser orientado a mudanças \\
\hline Saber trabalhar em equipe & Tomada de decisão & Ser persistente \\
\hline $\begin{array}{l}\text { Know-how técnico na área } \\
\text { de atuação }\end{array}$ & Ser um bom negociador & Ser um líder visionário \\
\hline
\end{tabular}

Fonte: Dornelas (2001).

Dolabela (2008, p. 24-35) cita as razões para a disseminação da educação empreendedora, dentre elas estão a autorrealização, o desenvolvimento social e o crescimento econômico, a criação de pequenas empresas, redução do desemprego, a preparação do empreendedor, a expansão da cultura intraempreendedora, fortalecimento do empreendedorismo spin-off e a educação sobre ética, cidadania e responsabilidade social.

A educação empreendedora vai além de despertar o interesse pelo empreendedorismo, ela desenvolve diversas habilidades e características que causam um forte impacto positivo na vida social, acadêmica e profissional dos estudantes. 


\section{METODOLOGIA}

Foi desenvolvida uma pesquisa aplicada, que de acordo com Fleury e Werlang (2017) são pesquisas que têm como objetivo elaborar diagnósticos, identificar e buscar soluções para problemas presentes nas atividades das instituições, organizações, grupos ou atores sociais. Foi empregada uma abordagem quantitativa, em que, segundo Ramos (2013), ocorrem tentativas de mensuração dos fenômenos sociais que o trabalho procura compreender e, qualitativa, trabalhos nos quais, segundo De Oliveira (2008) a vida humana é vista como uma atividade interativa e interpretativa.

A pesquisa tem um enfoque descritivo, que segundo Gil (1946) são pesquisas que têm como objetivo a descrição das características de determinada população ou fenômeno ou ainda o estabelecimento de relações entre variáveis.

Dados acerca do tema foram analisados, por meio de pesquisa documental, que de acordo com Gil (1946) são pesquisas que utilizam materiais que ainda não receberam tratamento analítico, ou que podem ser reelaborados de acordo com os objetivos da pesquisa. Foram analisados documentos oficiais do Instituto Federal de Pernambuco, incluindo documentos do campus Recife e dos cursos Técnico em Eletrônica e Técnico em Eletrotécnica.

Aos discentes, foi aplicado um questionário online com questões fechadas e abertas, que segundo Gil (1946) é um conjunto de questões respondidas pelos pesquisados. O questionário teve como objetivo identificar o ponto de vista dos estudantes dos cursos técnicos estudados em relação ao tema do trabalho, bem como sua ligação com a instituição e sua posição na sociedade como um todo. As perguntas relacionadas às características empreendedoras foram baseadas nas habilidades empreendedoras descritas por Dornelas (2001) na revisão de literatura.

Estudam nos cursos Técnico em Eletrônica e Técnico em Eletrotécnica 1010 estudantes, sendo, respectivamente, 456 e 554 estudantes em cada um dos cursos (IFPE, 2020b). Inicialmente o questionário foi aplicado entre os dias 18/05/2020 e 18/06/2020, no entanto com o intuito de aumentar a quantidade de respondentes, o período de aplicação foi estendido até o dia 28/06/2020. No total, o questionário obteve 68 respostas de estudantes do IFPE - Campus Recife dos cursos Técnico em Eletrônica e Técnico em Eletrotécnica. Os resultados do questionário serão analisados a seguir. 


\section{RESULTADOS E DISCUSSÃO}

Os dados analisados foram obtidos por meio de um questionário aplicado aos estudantes dos cursos técnicos estudados nas modalidades integrado e subsequente. A análise também foi realizada tendo em vista o Projeto Pedagógico do Curso Técnico em Eletrônica Integrado (IFPE, 2014c), o Projeto Pedagógico do Curso Técnico em Eletrônica Subsequente (IFPE, 2014d), o Plano do Curso Técnico em Eletrotécnica Integrado ao Ensino Médio (IFPE, 2014a) e o Plano do Curso Técnico em Eletrotécnica Subsequente (IFPE, 2014b).

O Instituto Federal de Pernambuco - Campus Recife, passou a ofertar os cursos técnicos estudados em 2014 (IFPE, 2014a, 2014b, 2014c, 2014d), tendo atualmente 456 estudantes matriculados no Curso Técnico em Eletrônica, sendo 310 estudantes da modalidade integrado e 146 da modalidade subsequente, e 554 estudantes matriculados no Curso Técnico em Eletrotécnica, destes 382 são da modalidade integrado e 172 na modalidade subsequente, como mostra o quadro 2. Nestes cursos, a quantidade de estudantes na modalidade de ensino integrado é significativamente maior do que a quantidade de alunos na modalidade subsequente. De acordo com dados do próprio campus do IFPE, no Curso Técnico em Eletrônica, os estudantes do ensino integrado representam aproximadamente $68 \%$ do total de estudantes, no Curso Técnico em Eletrotécnica esse número é bem próximo, representando em torno de $69 \%$ do total de estudantes do curso (IFPE, 2020b).

Quadro 2: Quantidade de estudantes por curso e modalidade.

\begin{tabular}{|l|c|c|c|}
\hline \multicolumn{1}{|c|}{ Curso } & Integrado & Subsequente & Total \\
\hline Técnico em Eletrônica & 310 & 146 & 456 \\
\hline Técnico em Eletrotécnica & 382 & 172 & 554 \\
\hline
\end{tabular}

Fonte: IFPE (2020b).

\section{Perfil dos estudantes}

As primeiras questões do formulário foram elaboradas para análise do perfil dos estudantes. Dentre elas estão questões acerca da faixa etária, sexo, renda familiar, etnia, modalidade de ensino, entre outras. 
Gráfico 1 (a): Idade dos respondentes.

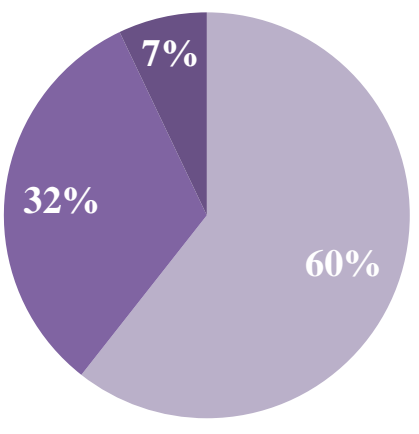

13 a 16 anos

- 17 a 20 anos

- Acima de 21 anos

Fonte: Própria (2020).
Gráfico 1 (b): Quantidade de estudantes por modalidade de ensino.

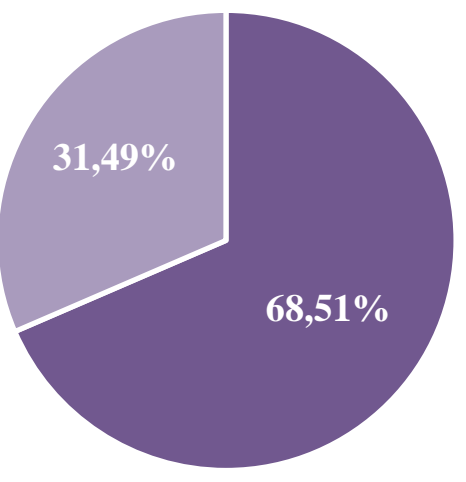

- Integrado $\quad$ Subsequente

Fonte: IFPE (2020b).

Dos estudantes respondentes, $60 \%$ têm entre 13 e 16 anos, $32 \%$ entre 17 e 20 anos e 7\% acima de 21 anos (gráfico 1 (a)). Fato que está possivelmente relacionado a disparidade da quantidade de estudantes da modalidade de ensino integrado ao ensino médio em relação aos estudantes da modalidade subsequente (gráfico 1 (b)).

Existe uma predominância de estudantes do sexo masculino, aproximadamente $84 \%$ dos estudantes são do sexo masculino, $14,7 \%$ são do sexo feminino e $1,5 \%$ preferiu não responder.

De acordo com Rodrigues e De Carvalho (2019), a quantidade de mulheres matriculadas em cursos de graduação é maior que a quantidade de homens, porém isso não se aplica nos cursos de ciências naturais, como física, engenharia e matemática.

Com base nos dados obtidos, é possível perceber que essa a realidade também se aplica aos cursos técnicos estudados do Instituto Federal de Pernambuco, já que são cursos com um foco maior em ciências naturais.

\section{Características empreendedoras}

Foram apresentadas frases que possuem relação com algumas das característícas empreendedoras identificadas por Dornelas (2001). As frases representam características como: ser orientado a mudanças, assumir riscos, ser um líder visionário, saber trabalhar em equipe e ser inovador. 
Gráfico 2: Frases relacionadas com características empreendedoras.

Sou uma pessoa dinâmica

Gosto de desenvolver novos trabalhos

Gosto de participar de projetos dentro do IFPE

Gosto de ajudar as pessoas

Gosto de trabalhar com outras pessoas

Sou uma pessoa inovadora

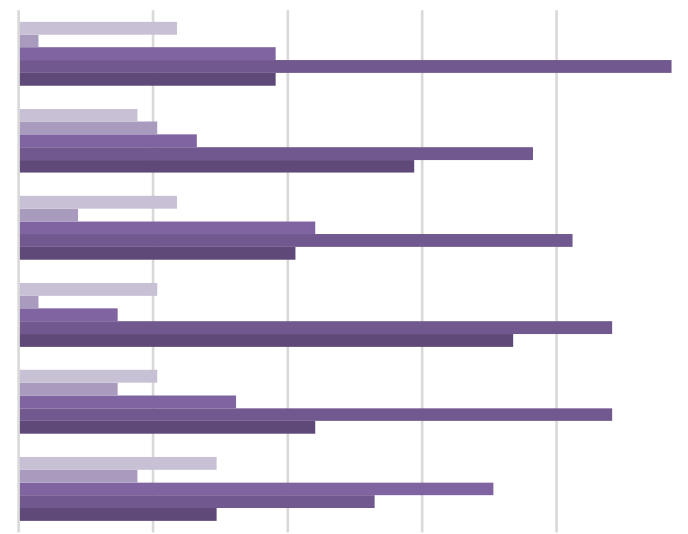

$0 \%$

$10 \%$

$20 \%$

$30 \%$

$40 \%$

$50 \%$

$60 \%$

$\square$ Discordo totalmente $\square$ Discordo $\square$ Indiferente ou Neutro $\square$ Concordo $\square$ Concordo totalmente

Fonte: Própria (2020).

Como visto no gráfico 2, em média, $64 \%$ dos estudantes responderam que concordam com estas frases, indicando que acreditam possuir características empreendedoras. É um bom número, mas ainda é menor do que a quantidade de estudantes que têm interesse em empreender, como é possível ver no gráfico 3.

Gráfico 3: Interesse em empreender nos estudantes dos cursos técnicos em Eletrônica e Eletrotécnica.

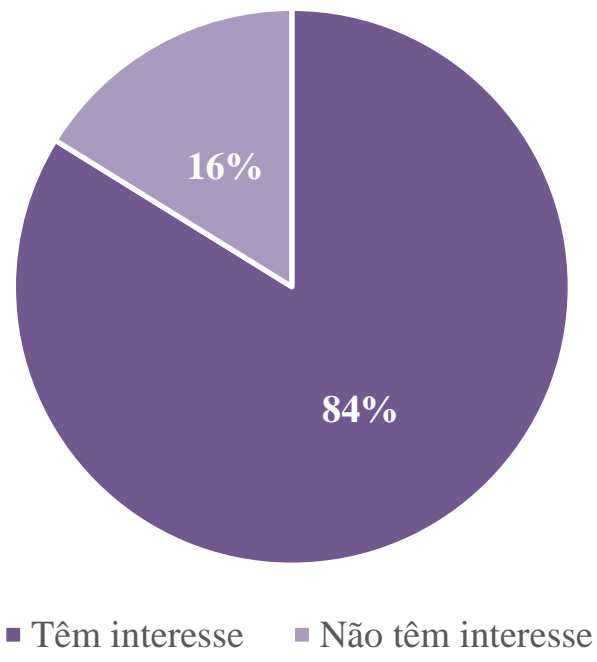

Fonte: Própria (2020). 
Gráfico 4: Conhecimento dos estudantes sobre educação empreendedora e interesse em empreender.

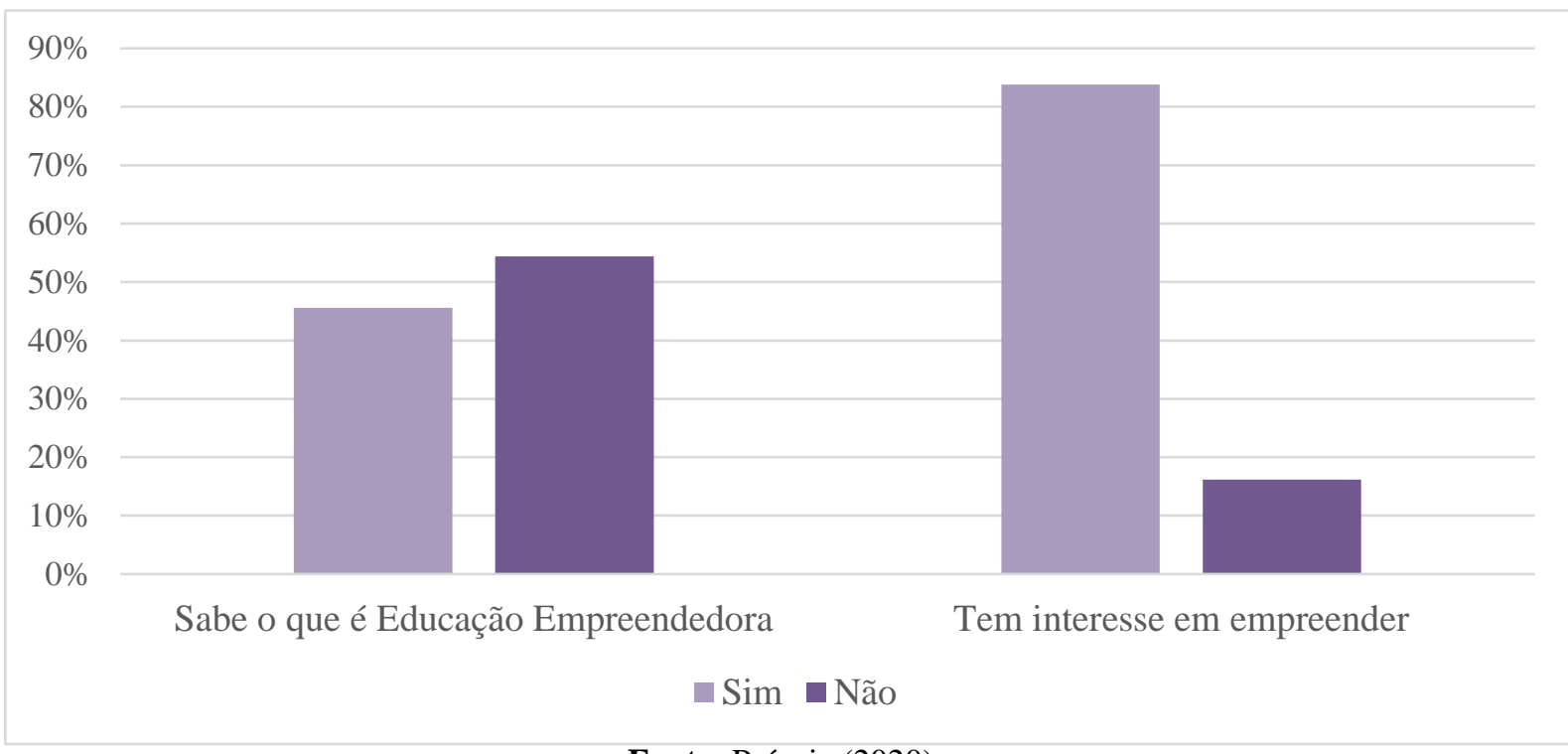

Fonte: Própria (2020).

Dentre os estudantes $84 \%$ têm interesse em empreender, no entanto apenas $46 \%$ afirmam que sabem o que é educação empreendedora (gráfico 4). Embora muitos discentes não tenham conhecimento sobre empreendedorismo e educação empreendedora, eles se interessam pelo assunto. Isso pode representar algum problema no ensino desse conteúdo.

Quadro 3: Experiência dos estudantes nas disciplinas de empreendedorismo.

\begin{tabular}{|l|l|}
\hline $\begin{array}{l}\text { Positiva, pois os conteúdos tinham relação com o mundo real e me ajudou a pensar } \\
\text { em empreender. }\end{array}$ & $33 \%$ \\
\hline $\begin{array}{l}\text { Foi uma disciplina que se tivesse sido ofertada no início do curso poderia ter } \\
\text { ajudado muito a compreender como fazer o conhecimento técnico se transformar em } \\
\text { uma oportunidade de negócio. }\end{array}$ & $22 \%$ \\
\hline $\begin{array}{l}\text { A disciplina foi boa, o professor tinha conhecimento, mas não tinha relação com } \\
\text { meu objetivo de vida. }\end{array}$ & $33 \%$ \\
\hline Nenhuma das opções anteriores. & $11 \%$ \\
\hline
\end{tabular}

Fonte: Própria (2020).

Dos estudantes que cursaram alguma disciplina de educação empreendedora, $88 \%$ relatam que sua experiência foi positiva e 55\% afirmam que a disciplina os ajudou a desenvolverem características empreendedoras, como mostra o quadro 3. Isso mostra que as disciplinas de educação empreendedora possuem um impacto na vida dos estudantes, desenvolvendo características empreendedoras e trazendo um interesse maior em empreender.

Os estudantes são potenciais empreendedores, disciplinas com conteúdo de educação 
empreendedora podem ajudá-los a desenvolverem características empreendedores e até mesmo se tornarem empreendedores, o que reforça os estudos de Adelar BAGGIO (2014) e Daniel BAGGIO (2014), quando falam que os brasileiros são potenciais empreendedores, e que é preciso apenas de estímulos.

Gráfico 5: Frequência em que os professores recomendam atividades que ajudam no desenvolvimento de características empreendedoras.

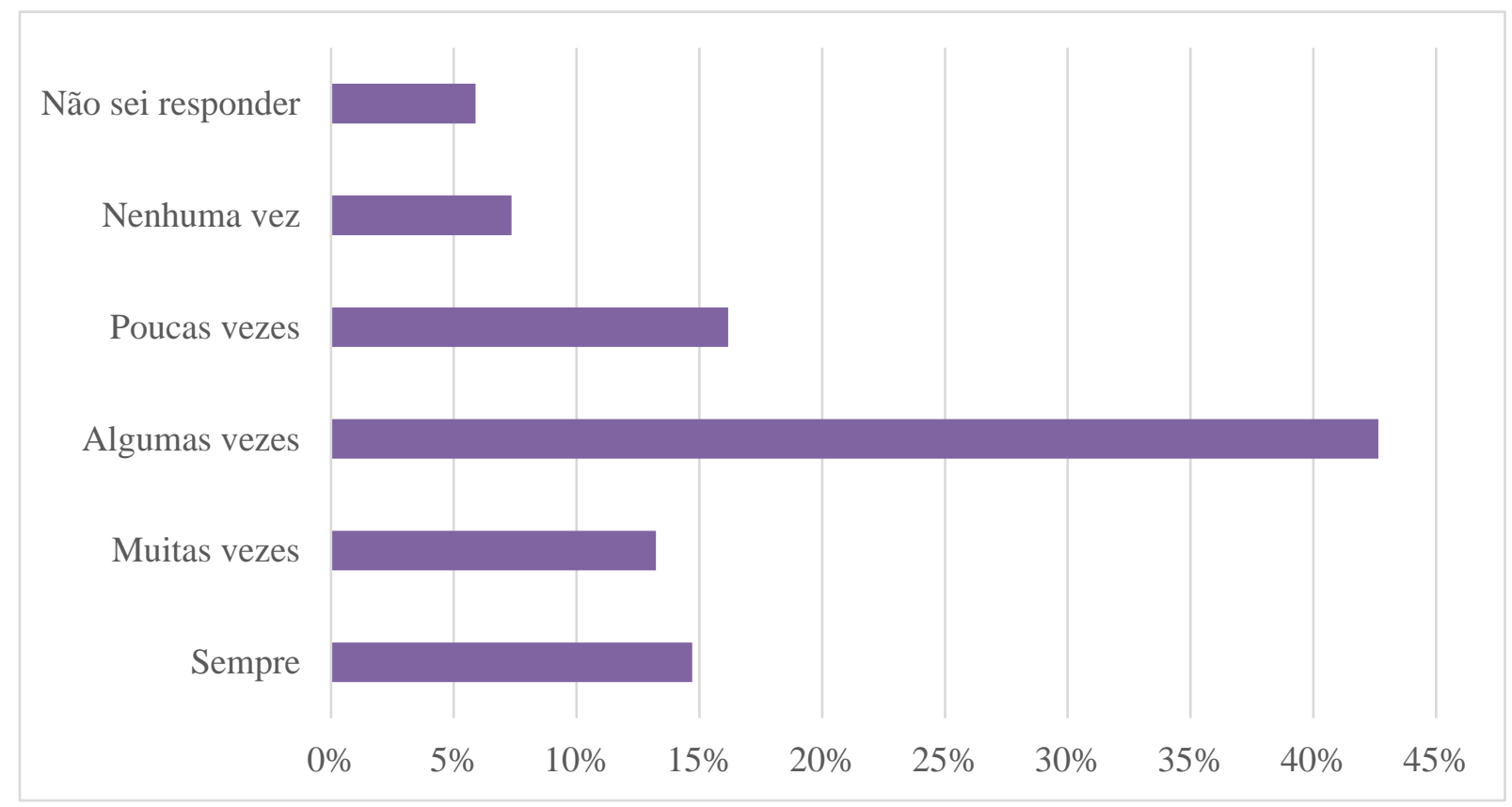

Fonte: Própria (2020).

De acordo com o gráfico 5, 43\% dos estudantes informaram que algumas vezes, os seus professores recomendam a realização de atividades que podem ajudar no desenvolvimento de características empreendedoras, como empresas juniores, hackathons, maratonas de empreendedorismo etc.

É importante que os professores, usando de sua influência, incentivem a participação dos alunos nesses tipos de eventos que possuem grande relevância no desenvolvimento de características e habilidades empreendedoras.

Atividades envolvendo educação empreendedora ou metodologias ativas de aprendizagem são mais efetivas quando os professores apresentam habilidades como: auxiliador, condutor, despertador, encorajador, estimulador, expansor, incentivador, motivador, sendo referência, guia e orientador (MICHELS et. al., 2018). 
Gráfico 6 (a): Interesse em empreender dos estudantes do Curso Técnico em Eletrônica.

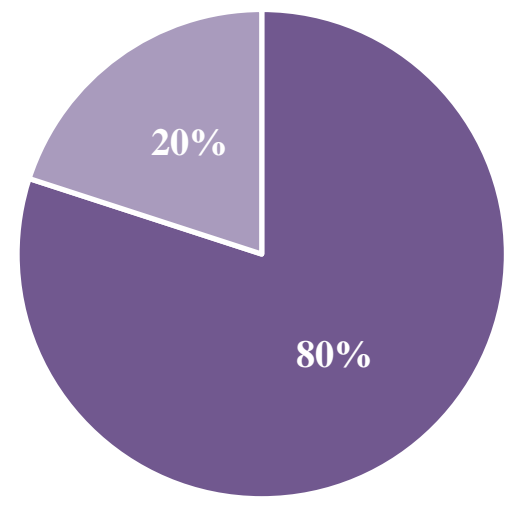

- Têm interesse " Não têm interesse

Fonte: Própria (2020).

Gráfico 6 (b): Interesse em empreender nos estudantes do Curso Técnico em Eletrotécnica.

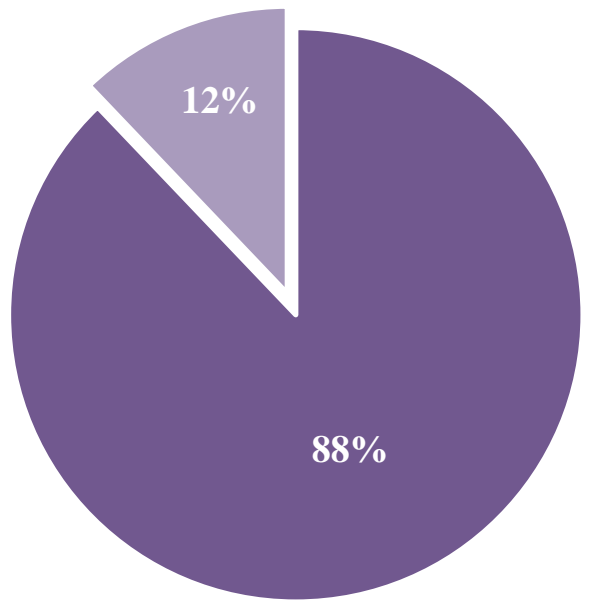

• Têm interesse - Não têm interesse

Fonte: Própria (2020)

Como é possível observar no gráfico 6 (a), $80 \%$ dos alunos dos cursos técnicos em Eletrônica têm interesse em empreender, já no gráfico 6 (b), nota-se que entre os discentes dos cursos técnicos em Eletrotécnica, esse número sobe para $88 \%$. A diferença do interesse em empreender entre os dois cursos não é tão grande, o interesse se mantém alto, acima de $80 \%$, nos dois cursos.

\section{Documentos do IFPE}

Os planos de curso dos cursos técnico em Eletrotécnica, nas duas modalidades, e os projeto pedagógicos dos cursos técnicos em Eletrônica, nas duas modalidades, têm como um dos objetivos formar profissionais com espírito empreendedor. Além disso, as matrizes curriculares de todos os cursos estudados possuem o componente curricular 
"Empreendedorismo".

Quadro 4: Competências a serem desenvolvidas no componente curricular "Empreendedorismo" por curso.

\begin{tabular}{|c|c|}
\hline Curso & Competência a serem desenvolvidas \\
\hline Técnico em Eletrotécnica Subsequente & $\begin{array}{c}\text { - Identificar oportunidades de negócios. } \\
\text { - Avaliar, planejar e elaborar projetos de } \\
\text { criação de pequenas empresas. } \\
\text { - Gerir negócios. }\end{array}$ \\
\hline Técnico em Eletrotécnica Integrado & $\begin{array}{l}\text { Desenvolver noções sobre a ação } \\
\text { empreendedora, a identificação de habilidades e } \\
\text { competências do Empreendedor, bem como sobre } \\
\text { a identificação e análise de oportunidades de } \\
\text { negócios, a sua implantação e gestão, em meio a } \\
\text { um ambiente cada vez mais competitivo e } \\
\text { exigente. }\end{array}$ \\
\hline $\begin{array}{l}\text { Técnico em Eletrônica Subsequente e } \\
\text { Técnico em Eletrônica Integrado }\end{array}$ & 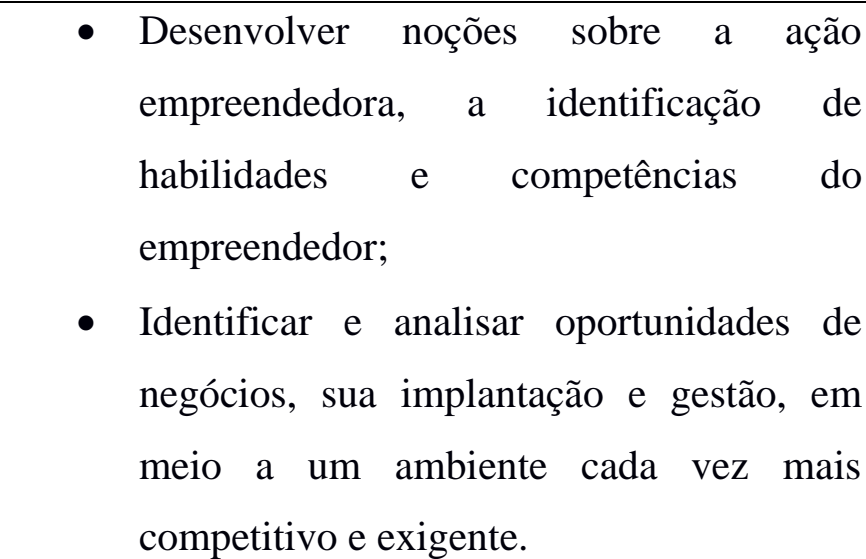 \\
\hline
\end{tabular}

Fonte: IFPE (2014a, 2014b, 2014c, 2014d)

As competências a serem desenvolvidas são semelhantes, e têm como principais objetivos o desenvolvimento de noções sobre o empreendedorismo e a identificação oportunidades de negócios (quadro 4). 
Gráfico 7: Conhecimento dos estudantes acerca da presença de disciplina de empreendedorismo em seu curso.

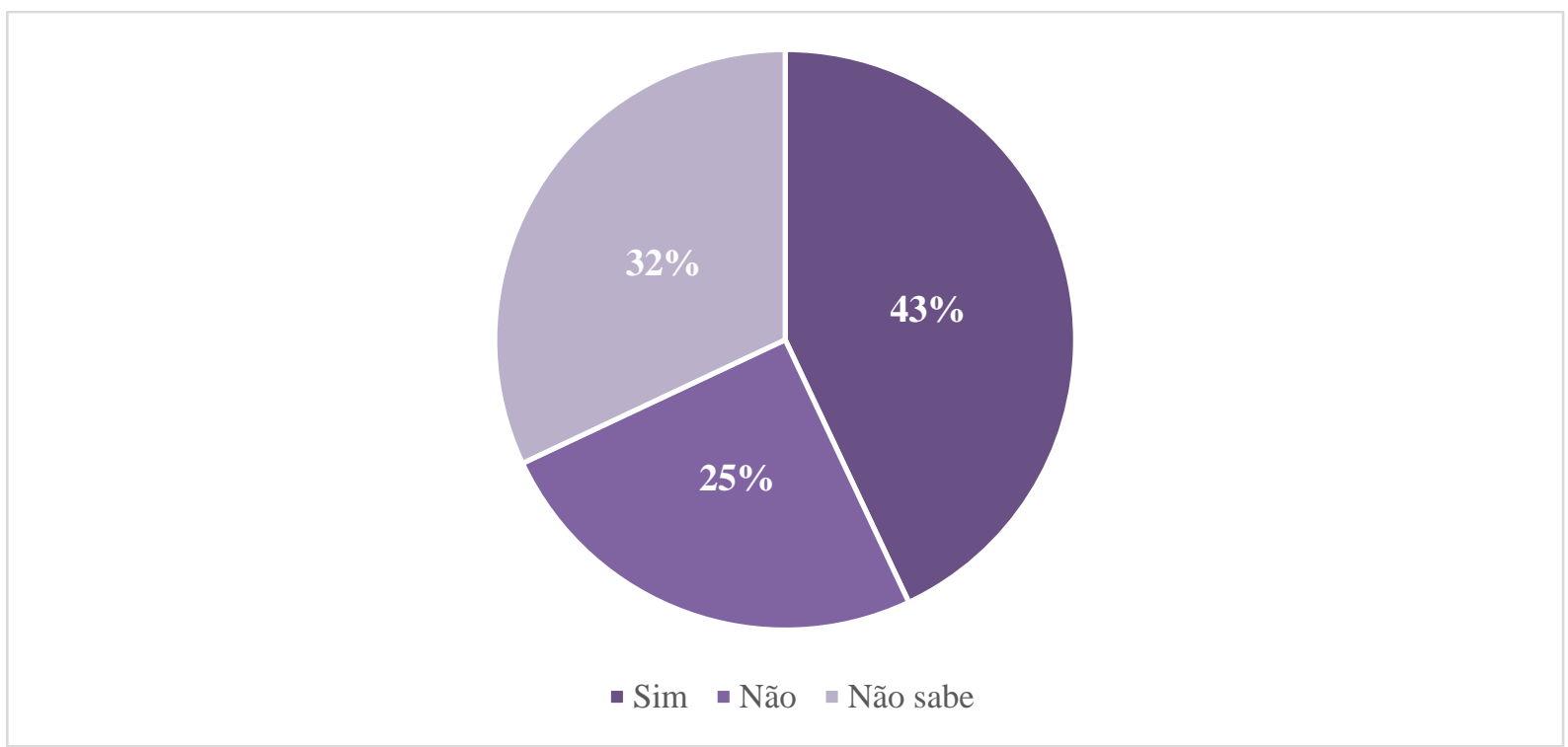

Fonte: Própria (2020).

Embora os dois cursos possuam a disciplina "Empreendedorismo", apenas 43\% dos estudantes têm conhecimento da existência dessa disciplina, já que o restante deles afirmam que seu curso não contém nenhuma disciplina de empreendedorismo ou não sabem responder (gráfico 7). Mesmo após cursarem a disciplina de empreendedorismo, 44\% dos alunos informam que não sabem o que é educação empreendedora (gráfico 8).

Gráfico 8: Conhecimento dos estudantes sobre educação empreendedora após cursarem a disciplina "Empreendedorismo"

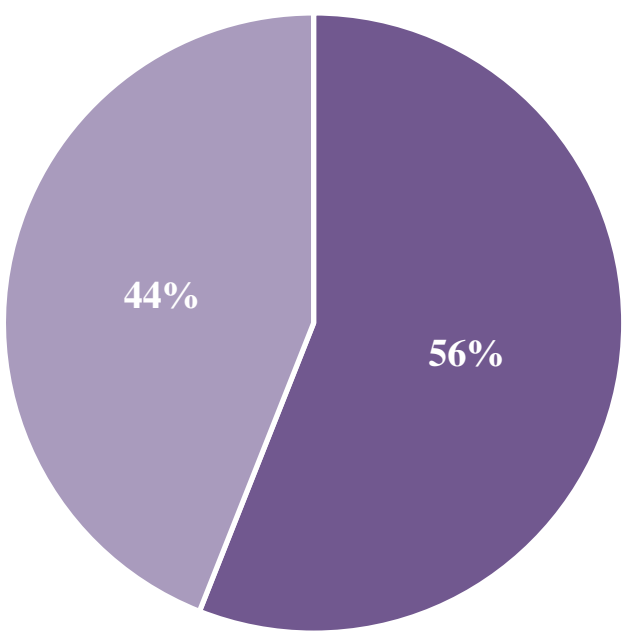

- Sabe o que é educação empreendedora - Não sabe o que é educação empreendedora

Fonte: Própria (2020).

Por meio dos resultados obtidos é possível observar que a maior parte dos estudantes tem interesse em empreender e possuem boa parte das características empreendedoras, apesar 
disso grande parte dos alunos não tem conhecimento sobre empreendedorismo. Ocasionalmente os professores recomendam aos seus alunos experiências que auxiliam no desenvolvimento de competências empreendedoras e despertam nos alunos o interesse em empreender. A disciplina responsável pelo conteúdo de educação empreendedora é chamada "Empreendedorismo". Ela aborda tópicos sobre as habilidades e competências do empreendedor, além de instruir o aluno a como gerir negócios e identificar possíveis oportunidades para empreender.

\section{CONCLUSÕES}

A educação empreendedora se torna de extrema importância na sociedade atual, visto que não se limita a formação de empreendedores, mas desenvolve nos estudantes características e habilidades fundamentais para o mundo do trabalho e até mesmo para a criação de empreendimentos de sucesso. Tendo em vista a importância deste tema, sua relação com o Instituto Federal de Pernambuco - Campus Recife, mais precisamente com os cursos técnicos abordados neste trabalho e os resultados obtidos, é possível perceber o crescimento do empenho da instituição em relação ao ensino do empreendedorismo.

A educação empreendedora nos cursos estudados tem maior destaque na disciplina "Empreendedorismo", onde são abordados temas relacionados a noções de empreendedorismo, identificação de habilidades e competências empreendedoras e a identificação de oportunidades de negócios. Ocasionalmente, os professores da instituição estimulam os estudantes a realizarem atividades que promovem o desenvolvimento de habilidades empreendedoras.

A maior parte dos estudantes tem interesse em empreender e indica possuir boa parte das características empreendedoras, mas afirmam não saber o que é a educação empreendedora, até mesmo após cursarem a disciplina "Empreendedorismo". Grande parte dos estudantes nem mesmo tem conhecimento de que seu curso possui uma disciplina com conteúdo sobre empreendedorismo. Já os que cursaram a disciplina, relatam que a experiência foi boa e que os fez pensar em empreender. Mesmo aqueles que acreditam que o empreendedorismo não tem relação com seus objetivos de vida afirmam ter passado por uma boa experiência.

Em conclusão, o Instituto Federal de Pernambuco - Campus Recife poderia tratar de forma mais ampla a educação empreendedora, tendo em vista o grande interesse por parte de 
seus estudantes, assim trazendo o empreendedorismo à tona desde o início dos cursos, através de eventos e programas tendo como objetivo preparar cada vez melhor os discentes da instituição para a atualidade do mercado e até mesmo tratando o empreendedorismo de maneira transdisciplinar, com formação aos professores para que cada um possa desenvolver trabalhos em suas disciplinas.

\section{REFERÊNCIAS}

BAGGIO, Adelar Francisco; BAGGIO, Daniel Knebel. Empreendedorismo: Conceitos e definições. Revista de Empreendedorismo, Inovação e Tecnologia, Passo Fundo, v. 1, n. 1, p. 25-38, jan. 2015. Disponível em: https://seer.imed.edu.br/index.php/revistasi/article/view/612. Acesso em: 06 jul. 2020. DOI https://doi.org/10.18256/2359-3539/reit-imed.v1n1p25-38.

BANERJI, Arup; CUNNINGHAM, Wendy; FISZBEIN, Ariel; KING, Elizabeth; PATRINOS, Harry; Robalino, David; TAN, Jee-Peng. Stepping Up Skills for More Jobs and Higher Productivity. Washington, DC: Banco Mundial, 2010. Disponível em: https://openknowledge.worldbank.org/handle/10986/27892. Acesso em: 24 set. 2020.

DE OLIVEIRA, Cristiano Lessa. Um apanhado teórico-conceitual sobre a pesquisa qualitativa: tipos, técnicas e características. Travessias, Cascavel, v. 2, n. 3, mar. 2010. Disponível em: http://e-revista.unioeste.br/index.php/travessias/article/view/3122. Acesso em: 26 ago. 2020.

DORNELAS, José Carlos Assis. Empreendedorismo: transformando idéias em negócios. Rio de Janeiro: Campus, 2001. ESTUDANTES do Campus Cabo fundam a $1^{a}$ Empresa Júnior do IFPE. IFPE. Cabo de Santo Agostinho, 24 ago. 2020a. Disponível em: https://portal.ifpe.edu.br/campus/cabo/noticias/estudantes-do-campus-cabo-fundam-a-1aempresa-junior-do-ifpe. Acesso em: 8 set. 2020.

DOLABELA, Fernando. Oficina do empreendedor. Rio de Janeiro: Sextante, 2008.

FILION, Louis Jacques. Empreendedorismo e Gerenciamento: Processos Distintos, Porém Complementares. RAE-Revista de Administração de Empresas, São Paulo, v. 40, n. 3, p. 817, set. 2000. Disponível em: http://www.scielo.br/scielo.php?script=sci_arttext\&pid=S003475902000000300013\&lng=pt\&nrm=iso. Acesso em: 06 jul. 2020. http://dx.doi.org/10.1590/S0034-75902000000300013.

FLEURY, Maria Tereza Leme; WERLANG, Sergio Ribeiro da Costa. Pesquisa aplicada: conceitos e abordagens. Anuário de Pesquisa GVPesquisa, São Paulo, nov. 2017. Disponível em: http://bibliotecadigital.fgv.br/ojs/index.php/apgvpesquisa/article/view/72796. Acesso em: 26 ago. 2020.

GIL, Antonio Carlos. Como elaborar projetos de pesquisa. 4. ed. São Paulo: Atlas, 2002.

IBGE, Coordenação de Cadastro e Classificações. Demografia das empresas e estatísticas de empreendedorismo: 2017. Rio de Janeiro: IBGE, 2018. Disponível em: 
https://biblioteca.ibge.gov.br/index.php/biblioteca-catalogo?view=detalhes\&id=2101671.

Acesso em: 08 set. 2020.

IFPE. Departamento Acadêmico de Controle de Sistemas Eletro-eletrônicos. Plano do Curso Técnico em Eletrotécnica (Integrado do Ensino Médio). Recife, 2014a. Disponível em: https://portal.ifpe.edu.br/campus/recife/cursos/tecnicos/integrados/eletrotecnica/projetopedagogico/ppc-eletrotecnica-integrado-2014-versao-final.pdf. Acesso em: 25 jul. 2020.

IFPE. Departamento Acadêmico de Controle de Sistemas Eletro-eletrônicos. Plano do Curso Técnico em Eletrotécnica (Subsequente). Recife, 2014b. Disponível em: https://portal.ifpe.edu.br/campus/recife/cursos/tecnicos/subsequente/eletrotecnica/projetopedagogico/plano-de-curso-eletrotecnica_subsequente_2014.pdf. Acesso em: 25 jul. 2020.

IFPE. Departamento Acadêmico de Sistemas, Processos e Controles Eletroeletrônicos. Projeto Pedagógico: Curso Técnico em Eletrônica Integrado. Recife, 2014c. Disponível em: https://portal.ifpe.edu.br/campus/recife/cursos/tecnicos/integrados/eletronica/projetopedagogico/ppc_eletronica_integrado.pdf. Acesso em: 23 jul. 2020.

IFPE. Departamento Acadêmico de Sistemas, Processos e Controles Eletroeletrônicos. Projeto Pedagógico: Curso Técnico em Eletrônica Subsequente. Recife, 2014d.

IFPE. Planilha quantitativa disponibilizada pela gestão. Recife, $2020 \mathrm{~b}$.

IFPE. Projeto Político Pedagógico Institucional - PPPI. Recife, 2012. Disponível em: https://portal.ifpe.edu.br/campus/recife/o-campus/documentos/projeto-politico-pedagogicodo-ifpe/projeto-politico-pedagogico-do-ifpe.pdf. Acesso em: 20 jul. 2020.

IIDV. Quem somos nós?. [S.1], [2018?]. Disponível em: https://pdv.institutoidv.org/blog/quem-somos-nos/. Acesso em: 10 set. 2020.

INDICADORES IBGE: pesquisa nacional por amostra de domicílios contínua. Quarto Trimestre de 2019. Rio de Janeiro: IBGE, v. 7, n. 4, fev. 2020. 52 p. Trimestral. Disponível em: https://biblioteca.ibge.gov.br/visualizacao/periodicos/2421/pnact_2019_4tri.pdf. Acesso em: 10 set. 2020.

MALACARNE, Robson; BRUNSTEIN, Janete; BRITO, Margarete Dias. Formação de Técnicos Agropecuários Empreendedores: O caso do IFES e sua participação na OBAP. Revista de Empreendedorismo e Gestão de Pequenas Empresas, [S.1.], v. 3, n. 2, p. 20-41, maio 2014. Disponível em: https://regepe.org.br/regepe/article/view/125. Acesso em: 06 jul. 2020. DOI: http://dx.doi.org/10.14211/regepe.v3i2.125.

MICHELS, Emillie; PASSIONI, Diego; MOREIRA, Fernanda Kempner; FERREIRA, Eliane Duarte; TEIXEIRA, Tatiani Fernandes. Educação empreendedora e o papel do professor. In: COLÓQUIO INTERNACIONAL DE GESTÃO UNIVERSITÁRIA, 18, 2018, Loja. Anais do XVIII Colóquio Internacional de Gestão Universitária [...]. Florianópolis: INPEAU/UFSC , 2018.2 Disponível https://repositorio.ufsc.br/handle/123456789/190489. Acesso em: 01 set. 2020.

PORTO DIGITAL. Armazém da Criatividade. [S.1], [2017a?]. Disponível em: https://www.portodigital.org/diferenciais/equipamentos/armazem-da-criatividade. Acesso em: 
11 set. 2020 .

PORTO DIGITAL. FAQ. [S.1], [2017b?]. Disponível em: https://www.portodigital.org/faq/. Acesso em: 11 set. 2020.

RAMOS, Marília Patta. Métodos Quantitativos e Pesquisa em Ciências Sociais: Lógica e Utilidade do Uso da Quantificação nas Explicações dos Fenômenos Sociais. Mediações. Londrina, v. 18, n. 1, p. 55-65, jan./jun. 2013. Disponível em: http://www.uel.br/revistas/uel/index.php/mediacoes/article/view/16807. Acesso em: 26 ago. 2020.

RODRIGUES, Jannyny de Oliveira Fogaça; DE CARVALHO, Sheyse Martins.

Evasão Feminina no Curso de Licenciatura em Física da UFT. In: WORKSHOP EM ENSINO DE FÍSICA DO TOCANTINS, 3, 2019. Tocantins. III Workshop em Ensino de Física do Tocantins [...]. Tocantins: UFT, 2019.

SEBRAE. Conheça o Programa Nacional de Educação Empreendedora. [S.1], [2019?]. Disponível em: https://cer.sebrae.com.br/programa-nacional-de-educacao-empreendedora/. Acesso em: 10 set. 2020. 